\title{
ROLE OF TRANXEMIC ACID TO REDUCE AND PREVENT POSTPARTUM HEMORRAHGE IN LOW RISK WOMEN
}

\author{
By
Mohammed Abolhassan Mahmoud, El-Rashidy M. Ibraheem and Badawy M. Ahmed \\ Department of Obstetrics and Gynecology, Faculty of Medicine, Al-Azhar University, \\ Assiut, Egypt \\ E-mail: $\underline{\text { m_abolhassan@yahoo.com }}$
}

\begin{abstract}
Background: To reduce maternal mortality and morbidity caused by bleeding, it is important to reduce the amount of bleeding during and after both normal vaginal delivery and lower segment cesarean section (LSCS). Tranexamic acid helps to reduce bleeding during and after both normal vaginal delivery and cesarean section.
\end{abstract}

Objective: To assess the safety and efficacy of Tranexamic Acid (TXA) in reducing blood loss during and after both NVD and elective CS.

Patients and Methods: The current study was conducted as controlled randomized trial on 200 women recruited from labor ward in Assiut Al -Azhar university Hospital. A total number of 100, 50 patients received tranexamic acid before induction of anesthesia in addition to oxytocin after delivery of the baby; in case of elective ceserian section the other 50 patients received tranxemic acid before second stage of labour in NVD the other 100 received only oxytocin after delivery in both NVD and CS.

Results: In the current study, there was significant difference between intervention and control groups as regards age. In the current study, no significant difference between intervention and control groups as regards gestational age at delivery $(\mathrm{p}<0721$ in NVD, $\mathrm{p}<0.726$ in CS). In the current study, no significant difference between intervention and control groups as regards preoperative hemoglobin (p 0.708 in NVD, p 0.107 in CS). Postoperative hemoglobin was significantly higher in intervention groups than control groups ( $p<0.001$ in NVD, $p<0.021$ in CS). In the current study, no significant difference between preoperative and post-operative prothrombin time and INR between intervention groups and control groups both in NVD and CS. In the current study, there was significant difference in postoperative measurements (SBP and DBP) in all groups.

Conclusion: The use of tranexamic acid prior to cesarean section and vaginal delivery was significantly effective in reducing blood loss during cesarean section with no observed maternal or neonatal side effects.

Key words: Prophylactic tranexamic acid, blood loss, elective cesarean section, NVD.

\section{INTRODUCTION}

PPH and its complications are a significant cause of maternal mortality and morbidity, particulary in developing countries, accounting for about $25 \%$ of direct maternal deaths (Geller et al., 2014 and Novikova \& Hofmeyr, 2015).

Post-partum hemorrhage is defined as loss of $>500 \mathrm{ml}$ within 24 hours of birth (Li et al., 2017). The four main causes of $\mathrm{PPH}$ are uterine atony, genital birth 
trauma, retained placental tissues and maternal coagulation disorders (Dyer and Buiwick, 2013).

While uterine atony is responsible for the majority of primary post- partum haemorrhage, the surgical obstetrical causes such as injury of the cervix, vagina, paravaginal spaces, perineum and episiotomy comprise about $20 \%$ all primary PPH (Henry and Carless 2012).

The occurrence rate of caesarean section (CS) has increased in both developed and developing countries, which would result in an increased risk of PPH. Although there has been a remarkable improvement in the prevention and treatment of $\mathrm{PPH}$ in recent years, deaths due to $\mathrm{PPH}$ remain relatively common in some parts of the world. To lower the occurrence rate of major morbidity and mortality due to PPH, it is very vital to reduce blood loss in CS and vaginal delivery though the incidence of early PPH (occurring within 24 hours of delivery) is lower in caesarean section than vaginal delivery, the former is a major surgery and causes greater blood loss. Hence, it is essential to prevent the blood loss effectively in a feasible way. Apart from obstetric, surgical and radiological interventions, pharmacologic management also plays an important role in this aspect. First line of therapeutic management for PPH is oxytocin (Matteson et al., 2013).

Other modalities include intravenous ergometrine, intra-muscular carboprost and misoprostol. Prohaemostatic drugs such as tranexamic acid provide a complementary biochemical haemostatic effect to the well- proven uterotonics, especially oxytocin. Systemic anti- fibrinolytic agents are widely used in surgery. A systematic review of randomised controlled trials of antifibrinolytic agents in elective surgical patients identified 211 randomised controlled trials (Movafegh et al., 2013).

The results showed that tranexamic acid reduced the risk of blood transfusion by $39 \%$. Tranexamic acid is an analogue of lysine that inhibits fibrinolysis by competitively binding to plasminogen. It prevents the lysis of formed clot by inhibiting activation of plasminogen and plasmin. It is ten times more potent than Amino- caproic acid (Movafegh et al., 2013).

Tranexamic acid has been shown to reduce uterine blood loss in non-surgical aspect. A study done on women with menorrhagia has showed significant reduction in mean menstrual blood loss in those treated with tranexamic acid (Perel et al., 2013).

A randomized controlled trial assessed tranexamic acid for the treatment of $\mathrm{PPH}$ and it showed that a high dose of tranexamic acid reduces blood loss in women with PPH (Prata et al., 2013).

Several randomised controlled trials have analysed the prophylactic role of tranexamic acid and have shown significant results in reducing blood loss. Tranexamic acid might reduce the need for hysterectomy, reduce the risk of severe anaemia and avoid the need for blood transfusion. Hence, this could contribute significantly to the goal of reducing maternal mortality (Kolev and Longstaff 2016).

The present work aimed to assess the safety and efficacy of Tranxemic acid on 
the amount of blood loss after both CS and vaginal delivery of patints at low risk of PPH.

\section{PATIENTS AND METHODS}

This study was conducted at the Department of Obstetrics \& Gynecology in Assuit Al- Azhar University Hospital.

Ethical committee approved the study protocol and an informed consent was obtained from every participant prior to commencing the study.

The study was conducted on two hundred women undergoing cesarean section and vaginal delivery and divided into:

Group 1: Tranexamic acid was given prior to surgery in study group in addition to the routine care $\{10$ units of oxytocin added to the intravenous drip soon after baby delivery\}. Tranexamic acid injection was prepared by diluting $1 \mathrm{~g}$ TA in $200 \mathrm{ml}$ of normal saline. TA was administrated as intravenous infusion (over 15minutes), at least 20 minutes prior to skin incision.

Group 2: Control group of cesarean section had routine care alone.

Group 3: TA was given prior to vaginal delivery (before 2nd stage of labor) at the same route in group1.

Group 4: Control group of vaginal delivery had routine care alone.

\section{Inclusion Criteria:}

Primi para pregnant woman with singletone pregnancy of age group in range of 20 up to 35 years.

\section{Exclusion Criteria:}

Polyhydraminos, macrosomia, preeclampsia, abnormal placenta, thrombophilia, anaemia, coagulopathy, cardiovascular, renal or liver diseases contraindication to any drug used in this study protocol. previous ceserian sections and multigravida, presence of varicosities at lower segment of the uterus, and intra operative complications like injury of uterine artery during ceserean section, or presence of tears at lateral vaginal walls, cervix or perineum during vaginal delivery.

All patients were subjected to full history taking, clinical examination (clinical criteria) and laboratory investigations (Complete blood count haemoglobin before and after surgery, liver functions, kidney functions and random blood sugar).

Blood loss was measured in both groups following placental delivery until the end of surgery. Blood collected in suction container was noted. Soaked mops and operation table perineal sheet was weighed by electronic scale before and after surgery. Hemoglobin and hematocrit value before and after surgery were estimated and the percentage of difference was compared.

\section{Statistical Analysis:}

Recorded data were analyzed using the statistical package for the social sciences, version 20.0 (SPSS Inc., Chicago, Illinois, USA). Quantitative data were expressed as mean \pm standard deviation (SD). Qualitative data were expressed as frequency and percentage.

\section{The following tests were done:}

- Independent-samples t-test of significance was used when comparing between two means. 
- Paired sample t-test of significance was used when comparing between related samples.
P-value was considered significant when $\mathrm{P}$-value $<0.05$.

\section{RESULTS}

No significant difference between intervention and control groups both in CS and NVD according to residence, BMI, and gestational age at delivery. There war significant difference according to age between intervention and control groups (Table 1).

Table (1): Personal data of the studied groups

\begin{tabular}{|c|c|c|c|c|c|c|}
\hline \multirow{2}{*}{\begin{tabular}{|l|} 
Parameters \\
Age: (years)
\end{tabular}} & \multicolumn{2}{|c|}{ NVD } & \multirow[b]{2}{*}{ P-value } & \multicolumn{2}{|c|}{ LSCS } & \multirow[b]{2}{*}{ P-value } \\
\hline & $\begin{array}{c}\text { Control } \\
(n=50)\end{array}$ & $\begin{array}{c}\text { Intervention } \\
(\mathbf{n}=\mathbf{5 0})\end{array}$ & & $\begin{array}{l}\text { Control } \\
(n=50)\end{array}$ & $\begin{array}{c}\text { Intervention } \\
(\mathbf{n}=\mathbf{5 0})\end{array}$ & \\
\hline \multicolumn{6}{|l|}{ Mean \pm SD } & \multirow{3}{*}{0.0307} \\
\hline Range & $22.12 \pm 2.71$ & $25.40 \pm 4.74$ & \multirow{2}{*}{0.000} & $24.12 \pm 4.86$ & $22.36 \pm 2.93$ & \\
\hline Residence: No. (\%) & $20.0-34.0$ & $20.0-35.0$ & & $20.0-35.0$ & $20.0-35.0$ & \\
\hline \multicolumn{3}{|l|}{ Rural } & \multirow{3}{*}{0.334} & & & \multirow{3}{*}{0.295} \\
\hline Urban & $37(74.0 \%)$ & $41(82.0 \%)$ & & $30(60.0 \%)$ & $35(70.0 \%)$ & \\
\hline BMI & $13(26.0 \%)$ & $9(18.0 \%)$ & & $20(40.0 \%)$ & $15(30.0 \%)$ & \\
\hline \multicolumn{6}{|l|}{ Mean \pm SD } & \multirow[b]{3}{*}{0.118} \\
\hline Range & $26.78 \pm 2.48$ & $26.65 \pm 2.76$ & \multirow[b]{2}{*}{0.805} & $26.92 \pm 3.08$ & $26.10 \pm 2.01$ & \\
\hline $\begin{array}{l}\text { Gestational age at } \\
\text { delivery (weeks) }\end{array}$ & $23.0-31.0$ & $23.0-33.0$ & & $21.0-33.0$ & $23.0-30.0$ & \\
\hline \multicolumn{6}{|l|}{ Mean \pm SD } & \multirow{3}{*}{0.727} \\
\hline \multirow[t]{2}{*}{ Range } & $38.38 \pm 1.05$ & $38.32 \pm 0.55$ & \multirow{2}{*}{0.721} & $38.80 \pm 0.81$ & $38.74 \pm 0.90$ & \\
\hline & $36.0-40.0$ & $38.0-40.0$ & & $38.0-40.0$ & $37.0-40.0$ & \\
\hline
\end{tabular}

No significant difference between intervention and control groups both in CS and NVD according to PT and INR. There was no significant difference between control and intervention groups both in CS and NVD preoperative. There is significant difference between groups postoperati according to $\mathrm{Hb}$ level (Table 2). 
Table (2): Comparison between intervention and control groups according to $\mathbf{H b}$ level, PT, and INR

\begin{tabular}{|c|c|c|c|c|c|c|}
\hline \multirow{2}{*}{\begin{tabular}{|l} 
Parameters \\
Pre-operative Hb:
\end{tabular}} & \multicolumn{2}{|c|}{ NVD } & \multirow[b]{2}{*}{ P-value } & \multicolumn{2}{|c|}{ LSCS } & \multirow[b]{2}{*}{ P-value } \\
\hline & $\begin{array}{l}\text { Control } \\
(n=50)\end{array}$ & $\begin{array}{c}\text { Intervention } \\
(\mathbf{n}=\mathbf{5 0})\end{array}$ & & $\begin{array}{l}\text { Control } \\
(n=50)\end{array}$ & $\begin{array}{c}\text { Intervention } \\
(\mathbf{n}=\mathbf{5 0})\end{array}$ & \\
\hline \multicolumn{6}{|l|}{ Mean \pm SD } & \multirow{3}{*}{0.112} \\
\hline Range & $11.24 \pm 1.07$ & $11.32 \pm 1.11$ & \multirow[t]{2}{*}{0.708} & $11.67 \pm 1.10$ & $11.32 \pm 1.08$ & \\
\hline Post-operative Hb: & $10.0-13.5$ & $10.0-13.8$ & & $10.1-13.4$ & $10.0-13.8$ & \\
\hline \multicolumn{3}{|l|}{ Mean \pm SD } & \multirow{3}{*}{0.001} & & & \multirow{3}{*}{0.021} \\
\hline Range & $9.25 \pm 1.04$ & $10.24 \pm 1.24$ & & $9.47 \pm 1.22$ & $10.29 \pm 1.11$ & \\
\hline P-value ${ }^{2}$ & $8.9-12.2$ & $8.9-12.9$ & & $8.8-12.2$ & $9.0-12.8$ & \\
\hline Pre-operative PT: & $0.000 *$ & $0.019^{*}$ & & $0.000^{*}$ & $0.000^{*}$ & \\
\hline \multicolumn{3}{|l|}{ Mean \pm SD } & \multirow{3}{*}{0.503} & & & \multirow{3}{*}{0.153} \\
\hline Range & $11.89 \pm 0.53$ & $11.98 \pm 0.76$ & & $12.15 \pm 0.82$ & $12.41 \pm 0.96$ & \\
\hline Post-operative PT: & $11.0-13.0$ & $11.0-13.7$ & & $11.0-14.0$ & $11.0-14.0$ & \\
\hline \multicolumn{3}{|l|}{ Mean \pm SD } & \multirow{3}{*}{0.749} & & & \multirow{3}{*}{0.219} \\
\hline Range & $11.84 \pm 0.55$ & $11.88 \pm 0.80$ & & $12.14 \pm 0.83$ & $12.36 \pm 0.94$ & \\
\hline P-value ${ }^{2}$ & $11.0-13.0$ & $11.0-14.0$ & & $11.0-14.0$ & $11.0-14.0$ & \\
\hline Pre-operative INR: & 0.090 & 0.569 & & $0.021 *$ & 0.207 & \\
\hline \multicolumn{3}{|l|}{ Mean \pm SD } & \multirow{3}{*}{0.581} & & & \multirow{3}{*}{0.112} \\
\hline Range & $1.12 \pm 0.08$ & $1.11 \pm 0.10$ & & $1.16 \pm 0.07$ & $1.11 \pm 0.07$ & \\
\hline Post-operative INR: & $1.0-1.2$ & $1.0-1.3$ & & $1.0-1.2$ & $1.0-1.2$ & \\
\hline \multicolumn{3}{|l|}{ Mean \pm SD } & \multirow{3}{*}{0.558} & & & \multirow{3}{*}{0.156} \\
\hline Range & $1.10 \pm 0.08$ & $1.11 \pm 0.09$ & & $1.15 \pm 0.07$ & $1.13 \pm 0.07$ & \\
\hline \multirow[t]{2}{*}{ P-value ${ }^{2}$} & $1.0-1.2$ & $1.0-1.3$ & & $1.0-1.2$ & $1.0-1.2$ & \\
\hline & 0.132 & 0.420 & & 0.828 & 0.340 & \\
\hline
\end{tabular}

No significant difference between control and intervention groups both in CS and NVD according to preoperative systolic and diastolic blood pressure measurements. There was significant difference between control and intervention groups according to 1-hour postoperative in NVD groups (Table 3).

Table (3): Comparison between preoperative and 1 hour postoperative systolic and diastolic blood pressure in intervention and control groups

\begin{tabular}{|c|c|c|c|c|c|c|}
\hline \multirow{2}{*}{$\begin{array}{ll}\text { Blood } \\
\text { Pressure }\end{array}$} & \multicolumn{2}{|c|}{ NVD } & \multirow[b]{2}{*}{ P-value } & \multicolumn{2}{|c|}{ LSCS } & \multirow[b]{2}{*}{ P-value } \\
\hline & $\begin{array}{l}\text { Control } \\
(n=50)\end{array}$ & $\begin{array}{l}\text { Intervention } \\
\quad(n=50)\end{array}$ & & $\begin{array}{c}\text { Control } \\
(n=50)\end{array}$ & $\begin{array}{l}\text { Intervention } \\
\quad(n=50)\end{array}$ & \\
\hline \multicolumn{3}{|c|}{ Pre-operative SBP: } & \multirow{3}{*}{0.352} & & & \multirow{3}{*}{0.424} \\
\hline Mean \pm SD & $113.00 \pm 7.89$ & $114.40 \pm 7.05$ & & $113.60 \pm 7.76$ & $112.40 \pm 7.16$ & \\
\hline Range & $100.0-130.0$ & $100.0-130.0$ & & $100.0-130.0$ & $100.0-120.0$ & \\
\hline \multicolumn{3}{|c|}{ Post-operative SBP: } & \multirow{3}{*}{0.001} & & & \multirow{3}{*}{0.494} \\
\hline Mean \pm SD & $104.00 \pm 9.31$ & $111.10 \pm 7.51$ & & $109.00 \pm 9.04$ & $110.20 \pm 8.45$ & \\
\hline Range & $90.0-120.0$ & $90.0-120.0$ & & $90.0-130.0$ & $90.0-120.0$ & \\
\hline P-value ${ }^{2}$ & $0.001 *$ & $0.001 *$ & & $0.001 *$ & $0.003^{*}$ & \\
\hline \multicolumn{3}{|c|}{ Pre-operative DBP: } & \multirow{3}{*}{1.000} & & & \multirow{3}{*}{0.692} \\
\hline Mean \pm SD & $73.80 \pm 6.02$ & $73.80 \pm 5.67$ & & $71.40 \pm 7.56$ & $72.00 \pm 7.56$ & \\
\hline Range & $60.0-80.0$ & $60.0-80.0$ & & $60.0-80.0$ & $60.0-80.0$ & \\
\hline \multicolumn{3}{|c|}{ Post-operative DBP: } & \multirow{3}{*}{0.001} & & & \multirow{3}{*}{0.086} \\
\hline Mean \pm SD & $66.30 \pm 6.04$ & $71.50 \pm 6.41$ & & $67.90 \pm 7.15$ & $70.40 \pm 7.27$ & \\
\hline Range & $55.0-80.0$ & $60.0-80.0$ & & $55.0-80.0$ & $55.0-80.0$ & \\
\hline P-value ${ }^{2}$ & $0.000^{*}$ & $0.000 *$ & & $0.000^{*}$ & $0.002 *$ & \\
\hline
\end{tabular}

Independent $\mathrm{t}$ - test, paired $\mathrm{t}$ - test. 


\section{DISCUSSION}

The increased frequency of PPH in the developing world is mainly due to expectant management because of lack of availability of medications used in the active management of the third stage (Prata et al., 2013).

During placental delivery, fibrinogen and fibrin are rapidly degraded, whereas plasminogen activators and fibrin degradation products increase due to activation of the fibrinolytic system. This activation can last up to 6-10 h postpartum causing more bleeding (Kolev and Longstaff, 2016).

Tranexamic acid competitively inhibits activation of plasminogen, thereby reducing conversion of plasminogen to plasmin (fibrinolysin), an enzyme that degrades fibrin clots, fibrinogen, and other plasma proteins, including the procoagulant factors $\mathrm{V}$ and VIII.

Tranexamic acid also directly inhibits plasmin activity, but higher doses are required than are needed to reduce plasmin formation. In vitro, the antifibrinolytic potency of tranexamic acid is approximately 5 to 10 times that of aminocaproic acid (Pabinger et al., 2017). It was used in gynecological bleeding and major trauma.

Thus, the current study was held to assess the efficiency of use of tranexamic acid in reducing blood loss in patients undergoing both ceserian section and vaginal delivery.

In this study, there wer 4 groups 2 study groups either CS or vaginal delivery each one contained 50 cases as well as 2 control groups either CS or vaginal delivery each one contained also 50 cases.
In the study of Gungorduk et al. (2013) There were 660 women who underwent elective CS were included in the study to determine the efficacy and safety of tranxemic acid in reducing blood loss during elective.

In the study of $X u$ et al. (2013), there were 174 primipara undergoing CS (88 given TA immediately before CS were compared with 86 others to whom TA was not given) to determine the efficacy of TA in reducing blood loss in patients after CS.

In our study, as regard personal data as (residence, BMI, and gestational age), there were no significant differences between intervention and control groups, but there was significant difference according to age.

In the study of $X u$ et al. (2013), the patients' characteristics in the two groups were similar, with no statistical difference between the two groups.

In our study, there was no significant statistical difference in the measurement of blood pressure preoperative and 1 hour postoperative between the groups. Postoperative hemoglobin was significantly higher in the intervention groups than in the control groups. Reduction in hemoglobin was significantly less in the study group than in the control group .

The previous study of Movafegh et al., (2013) showed that tranexamic acid significantly reduced the quantity of blood loss from the end of LSCS to 2 hours postpartum. It also significantly reduced the quantity of blood loss intraoperative. Abdel-Aleem et al. (2013) showed that tranexamic acid significantly reduced the blood loss in the study group. 
In our study, no significant difference between preoperative and post-operative measurements of prothrombin time and INR between intervention groups and control groups in both NVD and CS.

The included patients were those who were term, singleton, going for NVD and elective cesarean section. Patients with major maternal medical problem, patients with bleeding tendency, patient with high risk of thrombo-embolism, ante-partum hemorrhage, abnormal site of the placenta, macrosomic baby, twin pregnancy and polyhydramnios were excluded.

We used placebo in the current study, and this agreed with the study of Gungorduk et al. (2011).

Peitsidis et al. (2011) have found two cases of pulmonary embolism in tranexamic acid treated group.

\section{CONCLUSION}

The use of tranexamic acid prior to cesarean section is significantly effective in reducing blood loss during caesarean section with no observed maternal or neonatal side effects.

\section{REFERENCES}

1. Abdel-Aleem H, Alhusaini TK, AbdelAleem MA et al. (2013): Effectiveness of tranexamic acid on blood loss in patients undergoing elective cesarean section: randomized clinical trial. J Matern Fetal Neonatal Med 2013; 26 (17): 1705-1709.

2. Dyer RA, Buiwick AJ, Carvalho B (2013): Oxytocin for labour and caesarean delivery: implications for the anaesthesiologist. Current Opinion. Anesthesiology, 24(3): 255-61.

3. Geller SE, Goudar SS, Adams MG, Naik VA, Patel A, Bellad MB et al. (2014): Factors associated with acute postpartum haemorrhage in low-risk women delivering in rural India. International Journal of Gynecology and Obstetrics, 101(1): 9499.

4. Gungorduk K, Yıldırım G, Asıcıŏglu O, Gungorduk OC, Sudolmus S, Ark C. (2011): Efficacy of intravenous tranexamic acid in reducing blood loss after elective cesarean section: a prospective, randomized, double-blind, placebocontrolled study. Am J Perinatol. 2011 Mar; 28(3):233-40.

5. Henry DA, Carless PA, Moxey AJ, O'Connell D, Stokes BJ, Fergusson DA et al. (2012): Antifibrinolytic use for minimizing perioperative allogeneic blood transfusion. The Cochrane Library, https://www.ncbi.nlm.nih.gov/pubmed/2 1249650.

6. Kolev K, Longstaff C (2016): Bleeding related to disturbed fibrinolysis. British journal of haematology, 175(1): 12-23.

7. Li C, Gong Y, Dong L, Xie B, Dai Z (2017): Is prophylactic tranexamic acid administration effective and safe for postpartum hemorrhage prevention? A systematic review and meta-analysis. Medicine, 96(1): 215-221.

8. Matteson KA, Rahn DD, Wheeler TL (2013): Non-surgical management of heavy menstrual bleeding: A systematic review and practice guidelines. Obstetrics and Gynecology, 121 (3): 632.

9. Mayur G, Purvi P, Ashoo G, Pankaj D (2007): Efficacy of tranexamic acid in decreasing blood loss during and after cesarean section: a randomized case controlled prospective study. J Obstet Gynecol India, 57(3):227-30.

10.Movafegh A, Eslamian L, Dorabadi A (2013): Effect of Intravenous Tranexamic Acid Administration on Blood Loss During and After Cesarean Delivery. Obstetric Anesthesia Digest., 33(1):34-5. 
11.Novikova N, Hofmeyr GJ (2015): Tranexamic acid for preventing postpartum haemorrhage (Review) Copyright (C) 2011 The Cochrane Collaboration. Published by JohnWiley \& Sons, Ltd.

12.Pabinger I, Fries D, Schöchl H, Streif W, Toller W (2017): Tranexamic acid for treatment and prophylaxis of bleeding and hyperfibrinolysis. Wiener klinische Wochenschrift, 129(9-10):303-16.

13.Peitsidis P, Kadir RA. (2011): Antifibrinolytic therapy with tranexamic acid in pregnancy and postpartum. Expert Opin Pharmacother. 2011 Mar; 12(4):50316.

14.Perel $\mathrm{P}$, Ker $\mathrm{K}$, Morales Uribe $\mathrm{CH}$, Roberts I. (2013): Tranexamic acid for reducing mortality in emergency and urgent surgery. Cochrane Database Syst Rev 2013; 1: CD010245.
15.Prata N, Bell S, Weidert K (2013): Prevention of postpartum hemorrhage in low-resource settings: current perspectives. International journal of women's health, 5:737.

16. Xu J, Gao W, ju Y, (2013): Tranxemic acid for thew prevention of post- partum hemorrhage after ceserian section: adouble - blind randomized trial. Arch gynecol obstetric 2013, 287(3): 463-8. 


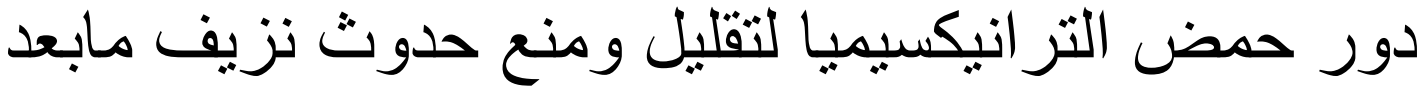 الو لادة في السبدات ذو ات الحمل الحمل منخفض الخطورة}

محمد ابوالحسن محمود، محمود ابراهيم الرشيدى، محمود احمد محمد بلوى

قسم التوليا وامراض النساء، كلية الطب، جامعة الازهر فرع اسيوط

E-mail: $\underline{\text { m_abolhassan@yahoo.com }}$

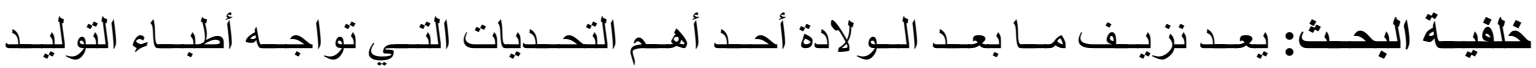

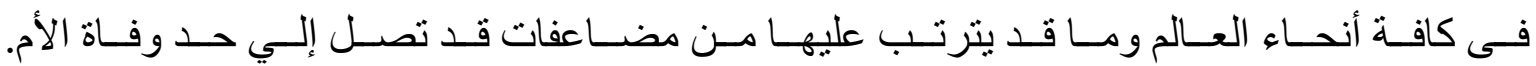

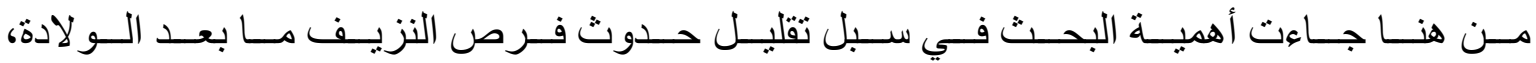

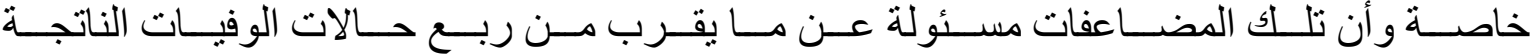

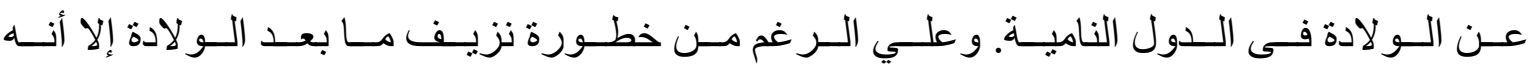

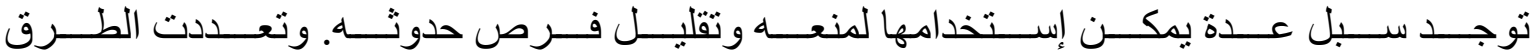

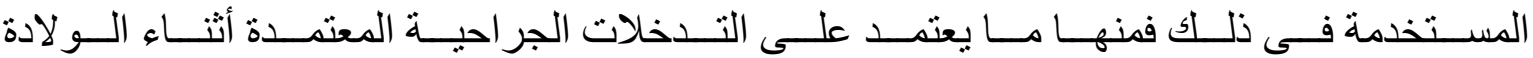

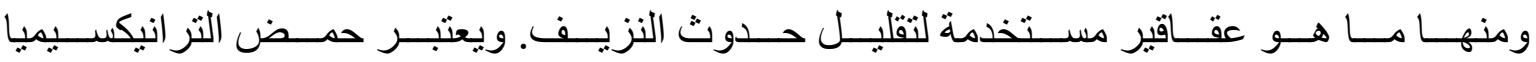

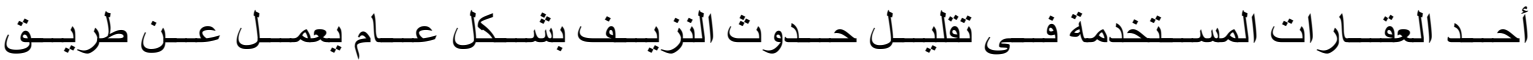
تقليل العو امل التي تزيد من سيولة الدم بالجسم و أثناء الو لادة بشكل خاص.

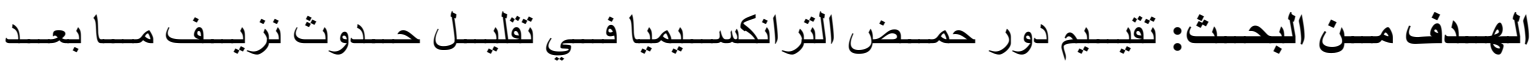
الو لادة فى السيدات ذوات المخاطر المنخفضة.

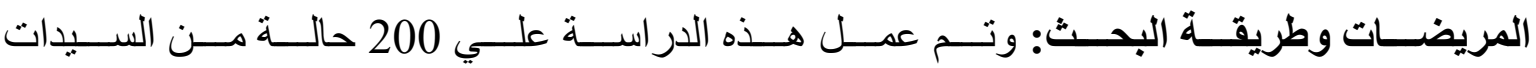

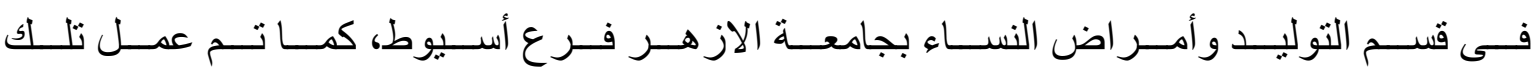

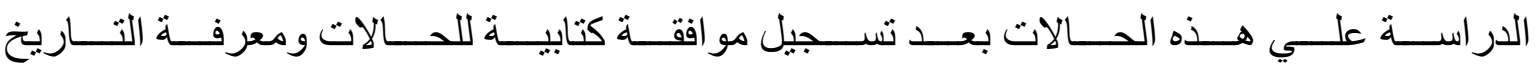

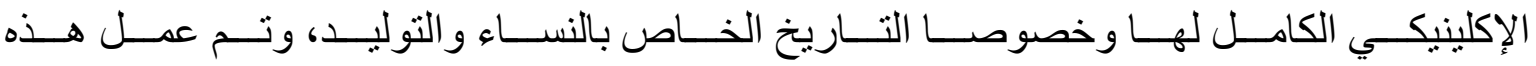

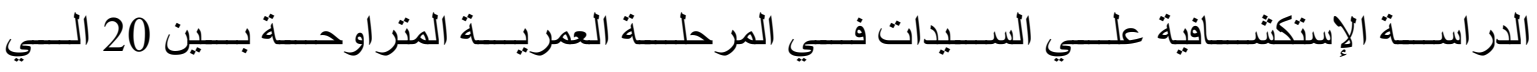

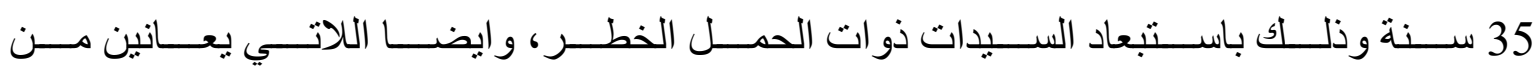

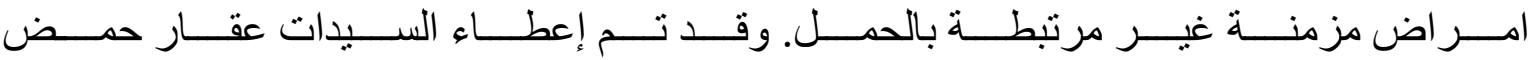




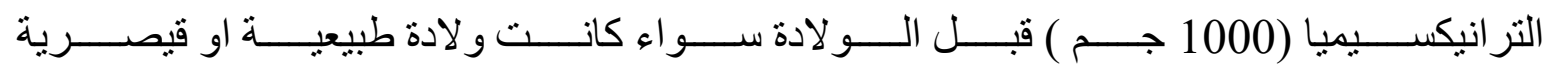
وملاحظة نسبة النزيف من عدمه.

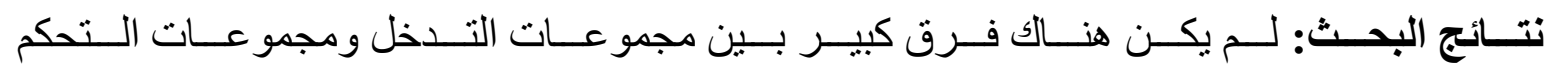

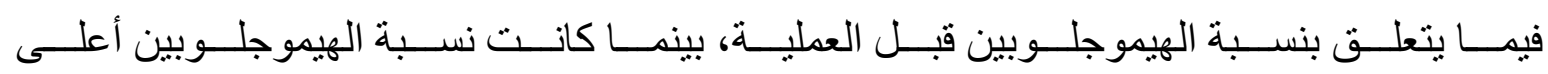

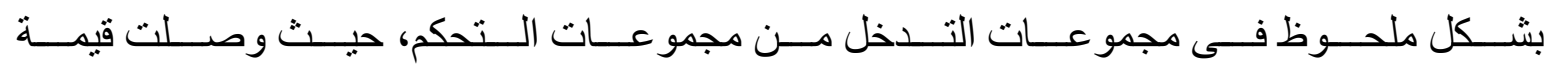

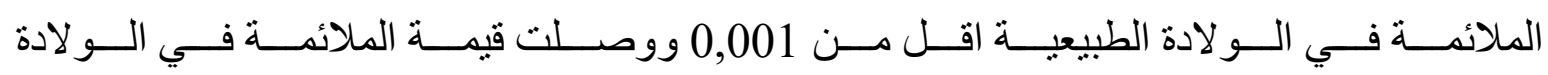

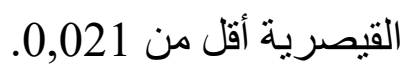

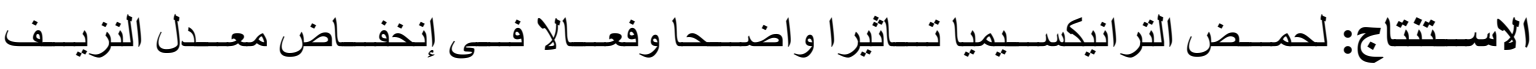
اثناء الو لادة وبعدها. 